\title{
Comparison of transforming growth factor beta expression in healthy and diseased human tendon
}

Henry C. J. Goodier ${ }^{1,2}$, Andrew J. Carr ${ }^{1,2}$, Sarah J. B. Snelling ${ }^{1,2}$, Lucy Roche ${ }^{1,2}$, Kim Wheway $^{1,2}$, Bridget Watkins ${ }^{1,2}$ and Stephanie G. Dakin ${ }^{1,2^{*}}$

\begin{abstract}
Background: Diseased tendons are characterised by fibrotic scar tissue, which adversely affects tendon structure and function and increases the likelihood of re-injury. The mechanisms and expression profiles of fibrosis in diseased tendon is understudied compared to pulmonary and renal tissues, where transforming growth factor (TGF) $\beta$ and its associated superfamily are known to be key drivers of fibrosis and modulate extracellular matrix homeostasis. We hypothesised that differential expression of TGF $\beta$ superfamily members would exist between samples of human rotator cuff tendons with established disease compared to healthy control tendons.

Methods: Healthy and diseased rotator cuff tendons were collected from patients presenting to an orthopaedic referral centre. Diseased tendinopathic (intact) and healthy rotator cuff tendons were collected via ultrasound-guided biopsy and torn tendons were collected during routine surgical debridement. Immunohistochemistry and quantitative real-time polymerase chain reaction were used to investigate the protein and gene expression profiles of TGF $\beta$ superfamily members in these healthy and diseased tendons.

Results: TGF $\beta$ superfamily members were dysregulated in diseased compared to healthy tendons. Specifically, TGF $\beta-1$, TGF $\beta$ receptor (R) 1 and TGF $\beta$ R2 proteins were reduced $(p<0.01)$ in diseased compared to healthy tendons. At the mRNA level, TGF $\beta$ R1 was significantly reduced in samples of diseased tendons, whereas TGF $\beta$ R2 was increased $(p<0.01)$. BMP-2, BMP-7 and CTGF mRNA remained unchanged with tendon disease.

Conclusions: We propose that downregulation of TGF $\beta$ pathways in established tendon disease may be a protective response to limit disease-associated fibrosis. The disruption of the TGF $\beta$ axis with disease suggests associated downstream pathways may be important for maintaining healthy tendon homeostasis. The findings from our study suggest that patients with established tendon disease would be unlikely to benefit from therapeutic TGF $\beta$ blockade, which has been investigated as a treatment strategy in several animal models. Future studies should investigate the expression profile of fibrotic mediators in earlier stages of tendon disease to improve understanding of the targetable mechanisms underpinning tendon fibrosis.
\end{abstract}

Keywords: Tendon, Tendinopathy, Fibrosis, TGF $\beta$

\footnotetext{
* Correspondence: stephanie.dakin@ndorms.ox.ac.uk

'Botnar Research Centre, Nuffield Department of Orthopaedics,

Rheumatology and Musculoskeletal Sciences, University of Oxford, Nuffield

Orthopaedic Centre, Windmill Road, Headington OX3 7LD, UK

${ }^{2}$ NIHR Oxford Biomedical Research Unit, Botnar Research Centre, University of

Oxford, Windmill Road, Oxford OX3 7LD, UK
}

(C) 2016 Goodier et al. Open Access This article is distributed under the terms of the Creative Commons Attribution 4.0 International License (http://creativecommons.org/licenses/by/4.0/), which permits unrestricted use, distribution, and reproduction in any medium, provided you give appropriate credit to the original author(s) and the source, provide a link to the Creative Commons license, and indicate if changes were made. The Creative Commons Public Domain Dedication waiver (http://creativecommons.org/publicdomain/zero/1.0/) applies to the data made available in this article, unless otherwise stated. 


\section{Background}

Musculoskeletal diseases are a common cause of pain and disability in well-resourced health systems [1]. Shoulder pain is the third most common cause of musculoskeletal pain, accounting for $2.4 \%$ of all general practitioner consultations annually in the UK [2]. Shoulder pain is frequently treated conservatively, but after 1 year $41 \%$ of patients have persistent pain [3]. Rotator cuff disease is the major cause of shoulder pain with the supraspinatus tendon being most frequently affected [4]. The onset of tendon pathology is associated with ageing, chronic overuse and genetic predisposition [5-7]. Shoulder pain is a major socio-economic burden and joint failure from rotator cuff tears can lead to secondary osteoarthritis [8].

Patients with rotator cuff disease may have tendinopathy (whereby the tendon is structurally intact) or a tendon tear. Tendon tears are sub-classified according to tear sizes ranging from small $(<1 \mathrm{~cm})$ to massive $(>5 \mathrm{~cm}$ in length) [9]. Tendons heal by fibrosis and the scar repair is frequently structurally and functionally inferior to normal tendon, increasing the risk of re-injury [10-13]. Treatment for shoulder tendinopathy includes physiotherapy, non-steroidal anti-inflammatory drugs (NSAIDs), and interventional treatments including local infiltration with glucocorticoids, platelet-rich plasma (PRP) and arthroscopic acromioplasty or rotator cuff repair. Non-operative strategies are associated with mixed patient outcomes [14]. Furthermore, surgical repairs of torn rotator cuff tendons are associated with high failure rates of up to $94 \%$ [15].

Inflammation is known to drive fibrotic repair in skin, liver, renal and pulmonary diseases. Signal transducer and activator of transcription (STAT)-6 pathways encompassing interleukin (IL)-13/IL-4 are thought to be the dominant pro-fibrotic axis for increasing collagen synthesis from fibroblasts and regulating alternatively activated macrophages [16-19]. Upregulation of IL-13 has been shown to mediate tissue fibrosis via transforming growth factor (TGF) $\beta$ [20]. TGF $\beta$ is the most frequently investigated effector of fibrosis and regulator of extracellular matrix (ECM) turnover. The TGF $\beta$ superfamily modulates a number of vital cellular processes in tissue development, differentiation and homeostasis. TGF $\beta-1$ is pivotal to wound healing processes and implicated in multiple fibrotic disease states including connective tissue fibrosis [21]. TGF $\beta$ is synthesised as a pro-peptide, and is abundant within the ECM, platelets and macrophages. Signalling is mediated through binding of active TGF $\beta$ to a heteromeric complex of TGF $\beta$ receptor (R)1 and 2, resulting in SMAD3 phosphorylation and activation of target genes. Macrophages, lymphocytes and resident stromal cells are key cell populations implicated in the propagation of fibrotic disease. Whilst inflammation has been identified in diseased tendons [22, 23], little is known about the inflammatory mechanisms driving tendon fibrosis.

Animal models have been used to identify potential treatment strategies for fibrotic diseases. These include manipulation of pro-fibrotic pathways through exogenous anti-TGF $\beta$, antisense-TGF $\beta$ gene, SMAD3 knockout, and macrophage depletion models [24-29]. Reducing TGF $\beta$ signalling diminishes the fibrotic phenotype of tendon but also reduces tissue tensile strength [30]. As part of the TGF $\beta$ superfamily, bone morphogenic proteins (BMPs) have previously been investigated for their role in tendon-to-bone healing [27, 31, 32] and in the stimulation of rotator cuff tendon-derived cells in tissue culture models [33]. These studies show BMP-2 and -7 induce collagen production in rotator cuff tendonderived cells, suggesting these BMPs could play a role in the development of tendon fibrosis.

Little is known of the mechanisms underpinning fibrosis in diseased human tendons. To our knowledge, no study to date has investigated TGF $\beta$ superfamily expression in diseased human tendons from living patients. The aim of this study was to investigate mRNA and protein expression of key TGF $\beta$ superfamily members in tissue samples from patients with established tendon disease compared to healthy control tendons. We hypothesised that expression of TGF $\beta$ superfamily genes and proteins would be dysregulated in diseased compared to healthy tendons.

\section{Methods \\ Diagnosis of rotator cuff tendon disease in patient cohorts}

Patients presenting to a referral shoulder clinic had failed non-operative treatment, including a course of physical therapy, and glucocorticoid injections into the sub-acromial space, and had experienced pain for a minimum of 6 months. Patients had not received glucocorticoid or PRP for 12 weeks before surgery. A shoulder specialist diagnosed sub-acromial impingement syndrome in all patients. Impingement tests were positive in all patients. High-definition ultrasound examination was performed in all patients to determine if there was evidence of a rotator cuff tear and also to identify abnormal echogenic changes at the supraspinatus footprint. Exclusion criteria for all patients in this study included previous shoulder surgery, dual shoulder pathological lesions, significant problems in the other shoulder, rheumatoid arthritis or systemic inflammatory disease, osteoarthritis or significant neck problems.

\section{Patient cohort for gene expression analysis}

Torn rotator cuff (supraspinatus, $\mathrm{n}=7$ ) and healthy hamstring $(\mathrm{n}=7)$ tendon tissue samples were collected 
to investigate mRNA expression of TGF $\beta$ superfamily members in these samples. Healthy hamstring tendons were collected from patients undergoing anterior cruciate ligament (ACL) reconstruction surgery from male and female patients aged between 22 and 49 (mean $31 \pm 9.5$ ) years. Torn supraspinatus tendon tissues were collected from male and female patients aged 40 to 67 (mean $52.5 \pm 9$ ) years (Table 1). Fresh tissue samples were immediately snap frozen in liquid nitrogen and stored at $-80{ }^{\circ} \mathrm{C}$ prior to RNA extraction.

\section{RNA extraction and CDNA synthesis}

Frozen tissue samples stored at $-80{ }^{\circ} \mathrm{C}$ were homogenised in $1 \mathrm{~mL}$ RNABee (AMS Biotechnology, UK) using an IKA Ultra Turrax T8 Homogeniser (Fischer Scientific, UK). RNA extraction was carried out as per the manufacturer's protocol using an RNeasy mini kit (Qiagen, Limburg, Netherlands) with an on-column DNA treatment using DNase 1 (Thermo Scientific, UK). RNA concentration and quality were determined by measuring the ratio of absorbance at 260:280 nm using a NanoDrop 100 spectrophotometer (Thermo Scientific, MA, USA), with all samples achieving a minimum ratio of 1.80 . RNA (250 ng) was reverse transcribed using a High Capacity Reverse Transcription Kit (4368813, Applied Biosystems, UK).

\section{Gene expression by quantitative real-time polymerase chain reaction}

cDNA was diluted to $2.5 \mathrm{ng} / \mu \mathrm{L}$ with RNase free water and $5 \mu \mathrm{L}$ was used in a $20 \mu \mathrm{L}$ quantitative polymerase chain reaction (qPCR) with Fast SYBR Green Master Mix (4385612, Applied Biosystems). Validated human primers included TGFB1 (QT00000728), TGFBR1 (QT00083412), TGFBR2 (QT00014350), BMP2 (QT00012544), BMP7 (QT00068936), and CTGF (QT00052899) (Qiagen). Duplicate reactions for each gene were run on a ViiA7
qPCR machine (Applied Biosystems, CA, USA) and the mean value for these duplicates calculated and used for analysis. Results were calculated using the $\Delta \Delta C_{t}$ method and normalized against $\beta$-actin and GAPDH reference genes. Results were consistent with both reference genes and data shown are normalized to $\beta$-actin.

\section{Patient cohort for immunohistochemistry}

For this controlled laboratory study, torn supraspinatus tendons were collected at the time of surgery from the edges of torn tendons from symptomatic male and female patients with full thickness tears aged between 50 and 78 years (Table 1). Samples of intact tendinopathic supraspinatus were collected from male and female patients at the time of arthroscopic acromioplasty. All patients had loss of shoulder function and/or shoulder pain as reflected in a median Oxford shoulder score (OSS) of 29 [34]. Healthy supraspinatus tendon samples were collected from patients who underwent surgery for shoulder instability and who had an intact non-degenerative supraspinatus tendon on ultrasound confirmed at surgery. Healthy patients were aged between 18 and 29 years (Table 1). For patients undergoing general anaesthesia for shoulder stabilization or arthroscopic acromioplasty, a biopsy was taken using ultrasound guidance whilst the patient was anaesthetized and prior to the surgical procedure. A percutaneous ultrasound-guided biopsy technique was performed as previously described [35] to acquire healthy tissue $5-10 \mathrm{~mm}$ posterior to the anterior edge of the tendon.

\section{Tissue processing}

Samples were immersed in $10 \%$ buffered formalin for 1 week. After fixation, tendons were processed using a Leica ASP300S tissue processor and embedded in paraffin wax. Tissues were sectioned at $4 \mu \mathrm{m}$ using a rotary microtome (Leica Microsystems Ltd, UK) and collected

Table 1 Patient demographics for the study group

\begin{tabular}{|c|c|c|c|c|c|c|}
\hline Cohort & $\mathrm{n}$ & Median age (years) & Sex (M:F) & History & Treatment & Median OSS \\
\hline Healthy supraspinatus & 10 & $24(18-29)$ & $9: 1$ & Shoulder instability & Shoulder stabilisation & N/A \\
\hline Healthy hamstring (mRNA) & 7 & $31(22-49)$ & $3: 4$ & ACL rupture & $A C L$ repair & N/A \\
\hline Tendinopathic supraspinatus & 23 & $54(36-73)$ & 13:10 & $\begin{array}{l}\text { Shoulder } \mathrm{S} \times 1-10 \text { years } \\
\text { (mean } 2.5 \text { years) }\end{array}$ & $\begin{array}{l}1-2 \text { steroid injections, } \\
\text { SAD } \pm \text { PRP }\end{array}$ & $29(11-38)$ \\
\hline \multirow[t]{4}{*}{ Torn supraspinatus } & 30 & $69.5(50-78)$ & $18: 12$ & 5 small & Rotator cuff repair & $20.5(7-35)$ \\
\hline & & & & 9 medium & & \\
\hline & & & & 9 large & & \\
\hline & & & & 7 massive & & \\
\hline \multirow[t]{3}{*}{ Torn supraspinatus (mRNA) } & 7 & $52.5(40-67)$ & $5: 2$ & 3 medium & Rotator cuff repair & $26(9-31)$ \\
\hline & & & & 2 large & & \\
\hline & & & & 2 massive & & \\
\hline
\end{tabular}


onto adhesive glass slides and baked at $60^{\circ} \mathrm{C}$ for 30 minutes and $37^{\circ} \mathrm{C}$ for 60 minutes.

For antigen retrieval, slides were baked at $60{ }^{\circ} \mathrm{C}$ for 60 minutes and combined deparaffinization and antigen retrieval was performed by submerging slides in FLEX TRS antigen retrieval fluid using a PT Link machine (Dako, Glostrup, Denmark). Immunostaining was performed using an Autostainer Link 48 machine using the EnVision FLEX visualisation system (Dako). Primary antibodies against TGF $\beta$ family mediators included TGF $\beta-1$ (ab64715), TGF $\beta$ R1 (ab31013) and TGF $\beta$ R2 (ab78419) (Abcam Cambridge, UK). Antibody binding was visualized using FLEX 3,3'-diaminobenzidine (DAB) substrate working solution and haematoxylin counterstain (Dako) as per protocols provided by the manufacturer. Isotype control antibodies included mouse $\operatorname{IgG}_{1}$, $\operatorname{IgG}_{2 \mathrm{a}}, \operatorname{IgG}_{2 \mathrm{~b}}$, IgG $\mathrm{Ig}_{3}$ and IgM, (Dako). All antibodies were validated in-house to ensure the recommended concentration produced positive staining with minimal artifact on supraspinatus tendon tissue. After staining, slides were rehydrated in alcohols and xylene and mounted using Pertex mounting medium (Histolab, Gothenburg, Sweden).

\section{Immunofluorescence for co-localization of TGF $\beta$ with macrophage markers}

Immunofluorescence staining of sections of massive supraspinatus tendon tears is described in detail elsewhere [22]. Briefly, after antigen retrieval, tissues were blocked in $5 \%$ goat serum (Sigma) at room temperature. Sections were incubated with the primary antibody cocktail (macrophage markers CD206 ab117644, CD163 LS_C174770 and pan TGF $\beta$ ab66043) diluted in $5 \%$ normal goat serum in phosphate-buffered saline (PBS) for 2 hours. Slides were washed in PBS with Tween and incubated in the secondary antibody cocktail (goat anti-

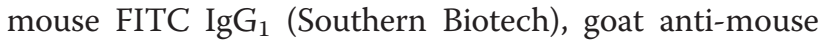
$\operatorname{IgG}_{2 a}$ Alexa Fluor 568, and goat anti-rabbit IgG Alexa Fluor 633 (Life Technologies)) diluted in $5 \%$ normal equine serum (Sigma) for 2 hours. After washing, sections were incubated in $2 \mu \mathrm{M}$ POPO- 1 nuclear counterstain (Life Technologies) diluted in PBS containing $0.05 \%$ Saponin (Sigma). Tissue autofluorescence was quenched with a solution of $0.1 \%$ Sudan Black B (Applichem). Slides were mounted using fluorescent mounting medium (VectaShield), sealed and stored at $4{ }^{\circ} \mathrm{C}$ until image acquisition. For negative controls the primary antibody was substituted for universal isotype control antibodies: cocktail of mouse $\operatorname{IgG}_{1}, \operatorname{IgG}_{2 \mathrm{a}}, \operatorname{IgG}_{2} \mathrm{~b}, \operatorname{IgG}_{3}$ and IgM (Dako) and rabbit immunoglobulin fraction of serum from non-immunised rabbits, solid phase absorbed (Dako). Stained slides were visualised on a Zeiss LSM 710 confocal microscope as previously described [22].
Image analysis for quantitative immunohistochemistry Twenty images of immunostained sections (or until exhausted) were taken on a Zeiss inverted microscope (Zeiss, Cambridge, UK) using Axiovision software (Zeiss) at $\times 100$ magnification with oil immersion. Images were collected systematically to ensure no overlap and to avoid areas of artefact or fold in the tissue sample. ImageJ (National Institutes of Health, Bethesda, Maryland, USA) was used to analyse the images, employing a previously validated algorithm that quantifies $D A B$ staining by a colour deconvolution method [36, 37]. The quantification system used compared the number of nuclei to the amount of immunopositive staining to account for tissue cellularity.

\section{Statistical analysis}

Statistical analysis was performed using GraphPad Prism 6 (GraphPad, CA, USA). Normality was tested using a Shapiro-Wilk test. Kruskal-Wallis tests were used to compare expression of TGF $\beta$ superfamily at mRNA and protein levels in samples of healthy, tendinopathic and torn tendons. $p<0.05$ was considered statistically significant.

\section{Study approval}

Ethical approval for this study was granted by the local research ethics committee: Oxfordshire REC B refs: 10/ H0402/24, 10/H0605/35, 09/H0605/111, 09/H0606/11. Full informed consent according to the Declaration of Helsinki was obtained from all patients.

\section{Results}

Diseased tendons show dysregulation of TGF $\beta$ family mediators at the mRNA level

Expression of TGFB1, TGFBR1, and TGFBR2 genes were investigated in torn rotator cuff and healthy hamstring tendons. TGFBR1 mRNA was decreased in diseased rotator cuff compared to healthy tendons $(p=0.048$, twofold); in contrast, TGFBR2 was increased $(p=0.048$, threefold) (Fig. 1). There was a trend for reduced TGFB1 in diseased compared to healthy hamstring tendons. BMPs have been shown to signal via homodimeric receptors from the TGF $\beta$ superfamily, and are also implicated in fibrotic pathways. There was no significant difference in $B M P 2$ mRNA between healthy hamstring and torn rotator cuff tendons (Fig. 1). BMP7 was not detected in torn rotator cuff tendons; however, this was not significantly different compared with healthy hamstring. Connective tissue growth factor (CTGF) was also investigated as a pro-fibrotic cytokine and downstream effector of TGF $\beta$. There was a trend for reduced CTGF in torn rotator cuff compared to healthy hamstring tendons. 


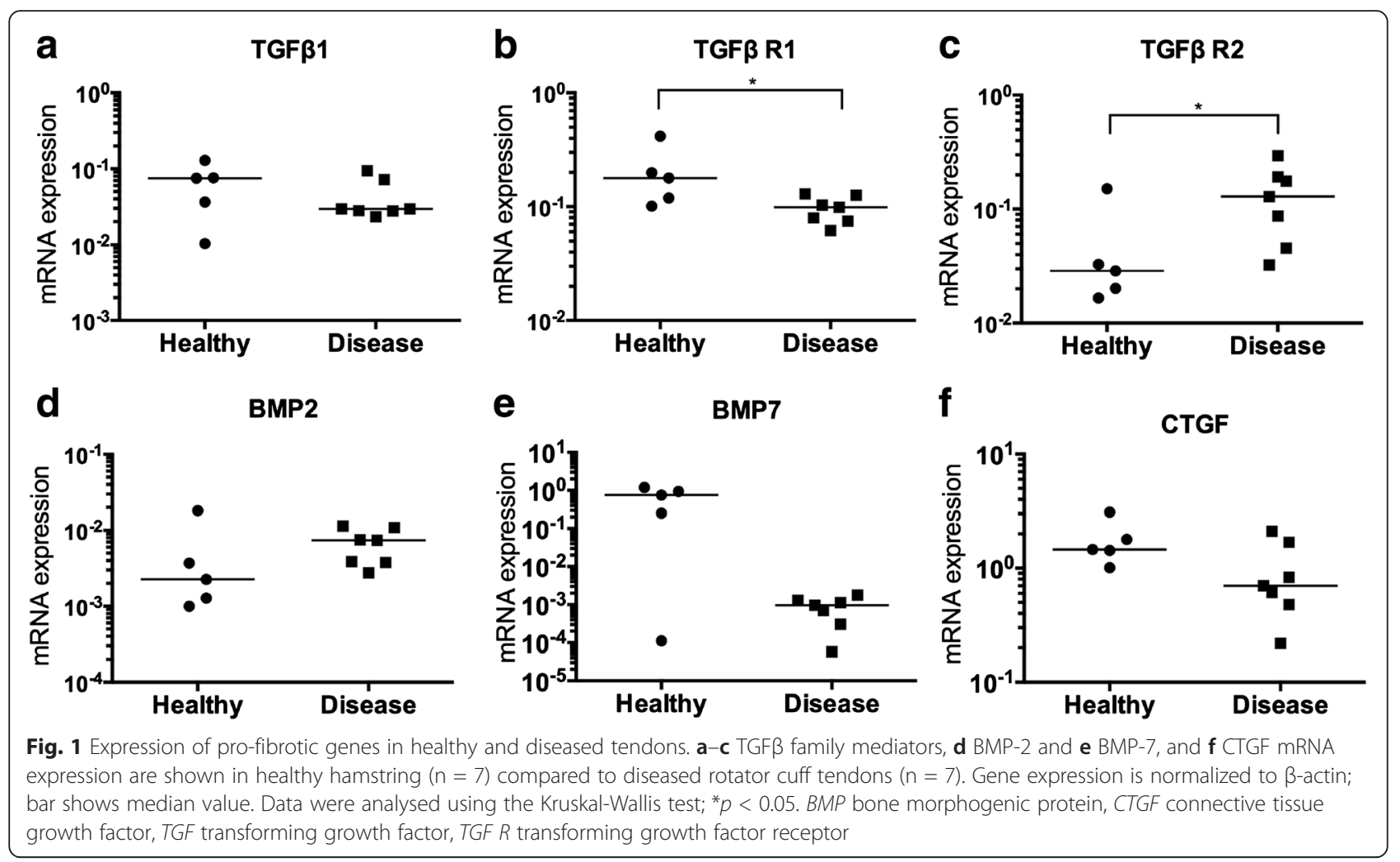

Histological assessment of diseased rotator cuff tendons Tendon tissues from patients with supraspinatus tendinopathy or tears showed marked disorganization of the tendon ECM and collagen fibrils and increased vascularity. Histological assessment of tendons collected from this cohort was performed on haematoxylin and eosin stained sections using the Bonar scoring system (0-12) evaluating tissue structure, and is reported in a previous published study [22]. Median and interquartile ranges of healthy supraspinatus tendons exhibited more normal tissue architecture (Bonar score of 2, range 1-2) compared to tendinopathic (7, range 6-8) and torn supraspinatus tendons (10, range $8.25-10)$.

\section{Diseased tendons show downregulation of TGF $\beta$ superfamily proteins}

Expression of TGF $\beta-1$, TGF $\beta$ R1, and TGF $\beta$ R2 proteins was investigated in healthy, tendinopathic and torn rotator cuff tendons (Fig. 2). Immunopositive staining for TGF $\beta$ superfamily proteins was identified in angiofibroblastic and ECM regions of tendons. Quantitative analyses of immunopositive staining showed expression of TGF $\beta-1$, TGF $\beta$ R1, and TGF $\beta$ R2 proteins were significantly reduced in diseased tendons compared to healthy samples (Fig. 3). Specifically, TGF $\beta-1$ protein was reduced in torn $(p=0.0123,2.6$-fold $)$ and tendinopathic $(p=0.0064$, threefold) compared to healthy tendons. TGF $\beta$ R1 protein was reduced in torn compared to healthy and tendinopathic tendons $(p=0.0002,30$-fold and $p=0.0018,21$-fold, respectively). TGF $\beta$ R2 was reduced in torn compared to healthy tendons ( $p=0.0087$, sevenfold reduction); tendinopathic tissues showed almost no expression of TGF $\beta$ $\mathrm{R} 2$ compared to healthy tendons $(p<0.00001,183$-fold reduction). Isotype control staining of diseased rotator cuff tendons is shown in Fig. 4.

\section{Macrophages in diseased tendons express TGF $\beta$}

Macrophages are known to be important immune cell populations in diseased rotator cuff tendons and their activation status has been shown to change with disease stage [22]. We investigated if myeloid cells in samples of chronic fibrosed tendon tears expressed pan-TGF $\beta$. Antibody labelling with macrophage markers CD206 and CD163 (representing STAT-6 and glucocorticoid receptor macrophage activation pathways, respectively) and pan-TGF $\beta$ showed co-localization of these three markers in sections of a massive supraspinatus tendon tear (Fig. 5).

\section{Discussion}

This study of diseased tendons from well-phenotyped patient cohorts investigates expression of the TGF $\beta$ superfamily members in healthy, tendinopathic, and torn tendons. Compared to healthy tendons, diseased tendons showed dysregulation of TGF $\beta$ superfamily members. We identify suppression of TGF- $\beta 1$ and TGF $\beta$ R1 

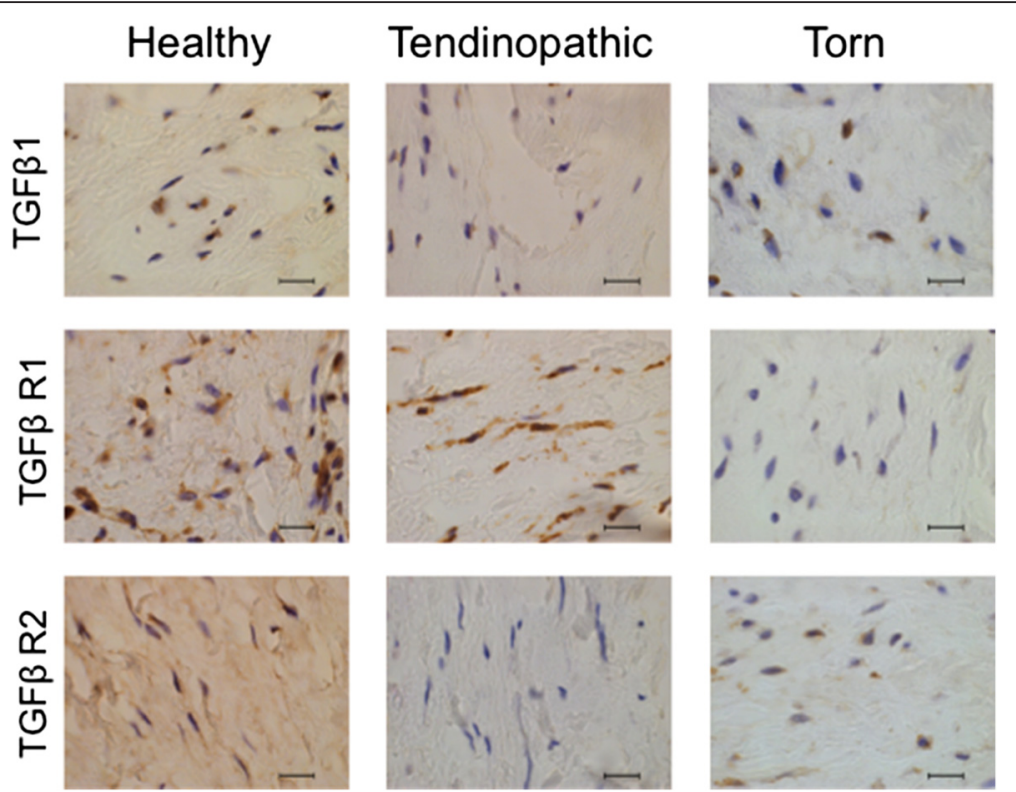

Fig. 2 Photomicrographs showing immunostaining for TGF $\beta 1$, TGF $\beta$ R1 and TGF $\beta$ R2 in healthy, tendinopathic and torn rotator cuff tendons. Representative images of DAB immunostaining (brown) are shown. Nuclear counterstain (blue) is haematoxylin. Scale bar $=20 \mu \mathrm{m}$. TGF transforming growth factor, TGF $R$ transforming growth factor receptor

mRNA and proteins in diseased compared to healthy tendons. Conversely TGFBR2 mRNA was increased in diseased tendons. This disruption of the TGF $\beta$ axis with tendon disease suggests these pathways may have important roles in tendon homeostasis.

The progression from rotator cuff tendinopathy to tear represents a continuum. Patients with tendon tears have reduced likelihood of repair [13]. We found no difference in symptom duration between patients with intact and torn tendinopathic tendons suggesting that pain is not always associated with tendon disease. Throughout the disease spectrum, the role of TGF $\beta$ superfamily mediators and the mechanisms underpinning tendon fibrosis remain understudied. Knowledge of these pathways is better described in fibrotic diseases of other connective tissues including pulmonary and renal tissues where increased levels of TGF $\beta$ and subsequent collagen production are reported in animal and human tissues [38-40]. In these tissues TGF $\beta-1$ is known to modulate the inflammatory response by influencing fibroblast and macrophage
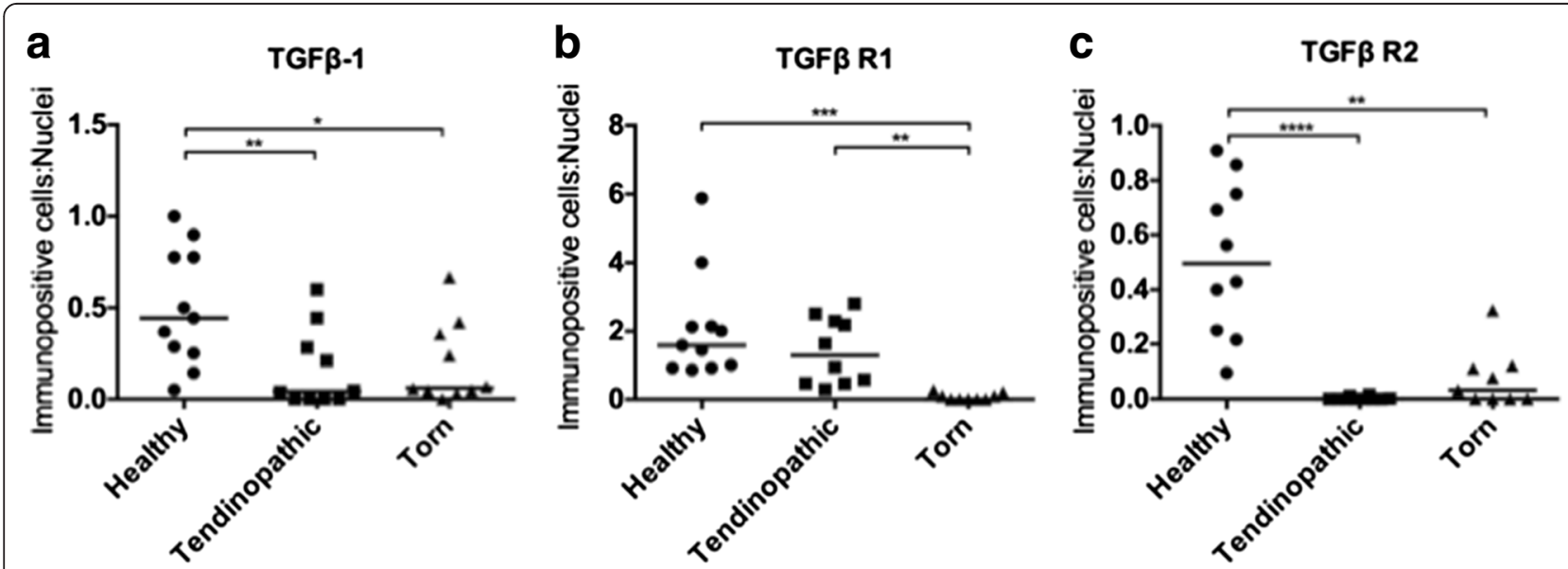

Fig. 3 Quantitative analysis of immunopositive staining showing dysregulation of TGF $\beta$ family proteins in diseased compared to healthy rotator cuff tendons. a TGF $\beta-1$ : healthy $(n=11)$, tendinopathic $(n=10)$, torn $(n=10)$; b TGF $\beta$ R1: healthy $(n=10)$, tendinopathic $(n=10)$, torn $(n=9)$; and c TGF $\beta$ R2: healthy $(n=10)$, tendinopathic $(n=10)$, torn $(n=9)$. Bar represents the median value. Data were analysed using the Kruskal-Wallis test; ${ }^{*} p<0.05{ }^{* *} p<0.01{ }^{* * *} p<0.001{ }^{* * *} p<0.0001$. TGF transforming growth factor, TGF $R$ transforming growth factor receptor 


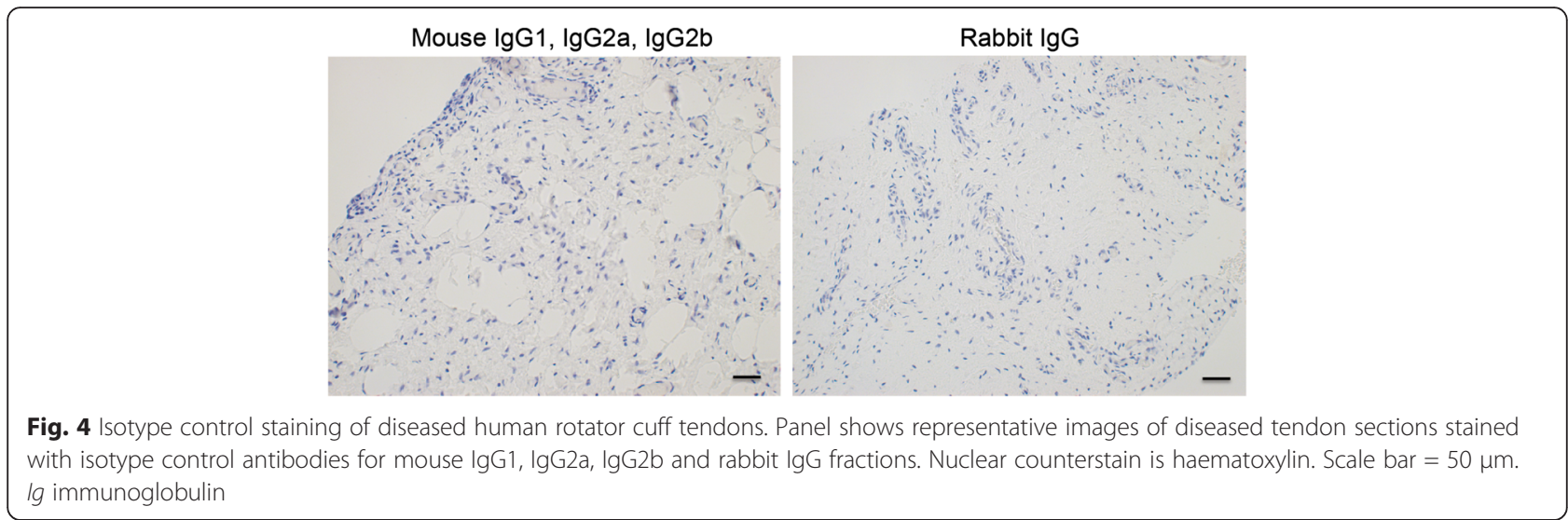

recruitment, stimulating collagen production and downregulating proteinase activity $[18,41]$. TGF $\beta$ has been shown to regulate epithelial-mesenchymal transition (EMT), potentially generating another source of collagen-producing cells [42]. In tendon, TGF $\beta$ is stored in the ECM and released in response to exercise and strain, regulating collagen synthesis and acting as a mechanical transducer [43, 44]. Sakai et al. showed an increase in total TGF $\beta$ protein when comparing tissue from patients with rotator cuff tendon tears and anterior shoulder instability [45]. In contrast, Fenwick et al. found no evidence of TGF $\beta-1$ protein in chronic tendinopathy or normal cadaveric human tendon tissues [46]. Chang et al stimulated and inhibited TGF $\beta$-induced collagen production in a surgical animal model to investigate flexor tendon adhesions demonstrating the importance of TGF $\beta$ in fibrotic healing [24].

In this study, we show that TGF $\beta-1, \operatorname{TGF} \beta$ R1 and TGF $\beta$ R2 protein levels are reduced in diseased compared to healthy rotator cuff tendons. We propose this could be a protective response to limit the hypertrophic fibrosis characteristic of tendon disease. Healthy rotator cuff tendons showed a variable range of expression of TGF $\beta$ receptors and ligands, perhaps demonstrating more active regulation of tissue homeostasis by TGF $\beta$ in healthy compared to diseased tendons. This suggests an important homeostatic function similar to those proposed in skin, cartilage and vascular tissue where dysregulation can result in disease [47-51]. It is conceivable that the downregulation of TGF $\beta$ superfamily proteins in established disease could further reduce the ability of the tendon to heal. This may be exacerbated in torn tendons by their reduced ability to transmit strain, which would then suppress the mechanical stimulus to regulate TGF $\beta$ signalling [43]. Fibrotic pathways independent of TGF $\beta$, such as tumour necrosis factor alpha, may be activated resulting in them becoming a more dominant driving force in chronic tendon disease [52].

TGF $\beta$ mRNA and protein have been shown to increase in animal models of acute-stage tendon healing. However, these models of surgical tendon transection may not accurately recapitulate chronic human tendon pathology $[53,54]$. The tendon samples used in the current study represent chronic-stage tendon disease. We speculate that expression of TGF $\beta$ family mediators in human rotator cuff tendons would be increased during acutestage pathology, and then decline in chronic disease as reported in the current study. Future work should investigate the temporal regulation of members of the TGF $\beta$ superfamily and of alternative fibrotic pathways including
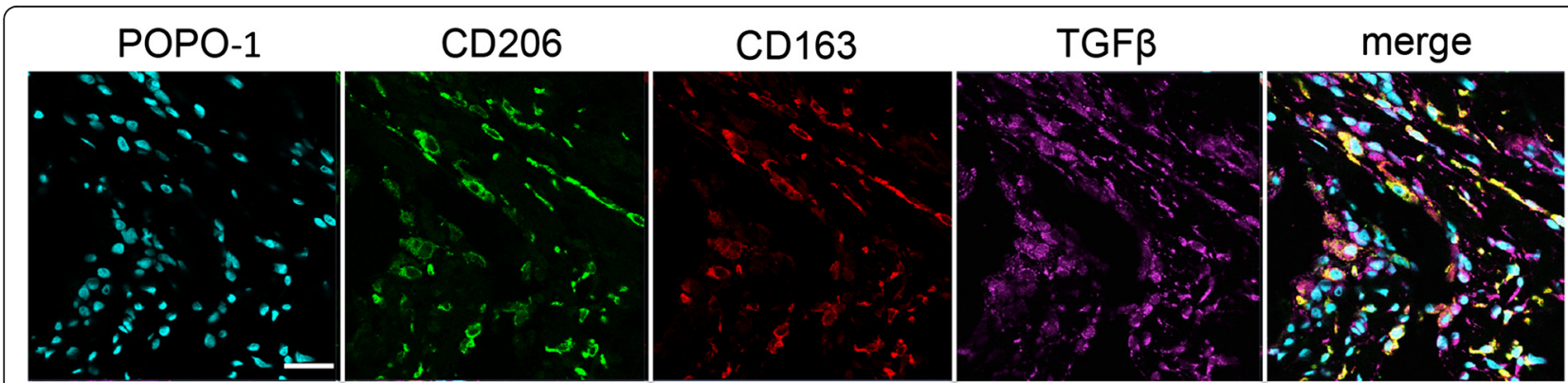

Fig. 5 Representative immunofluorescence images of a massive supraspinatus tendon tear stained for macrophage activation markers including those in the STAT-6 pathway (CD206, green), the glucocorticoid receptor pathway (CD163, red) with pan-TGF $\beta$ (purple). Cyan represents POPO-1 nuclear counterstain. Scale bar $=20 \mu \mathrm{m}$. CD cluster of differentiation, TGF transforming growth factor 
Wnt, PI3K and vascular endothelial growth factor in patients with early through to established tendon disease.

Although we demonstrate downregulation of TGF $\beta$ signalling mediators with established tendon disease, TGFBR2 mRNA was upregulated in tendon tears. This observation may represent a potential aberration in the translation of TGFBR2 mRNA into protein. Alternatively, upregulation of TGFBR2 could be an attempt to support higher levels of alternatively activated macrophages [55]. We identified CD206 ${ }^{\text {high }}$ and $\mathrm{CD} 163^{\text {high }}$ macrophages that co-expressed pan-TGF $\beta$ in a massive tendon tear, suggesting M2 macrophages may be a source of TGF $\beta$ in advanced stage tendon disease.

TGF $\beta$ pathways have been investigated as potential therapeutic targets to modulate fibrosis, adhesions, and hypertrophic scarring [24, 26, 28, 30]. However, antiTGF $\beta$ models also resulted in reduced tissue tensile strength $[30,56]$. In a model of stress-shielding, exogenous TGF $\beta$ helped maintain tendon strength, whereas anti-TGF $\beta$ accelerated the loss of strength [56]. These studies and our results support the concept that TGF $\beta$ has a fundamental role in tendon homeostasis as well as playing a role in fibrosis.

CTGF is an effector cytokine of TGF $\beta$ that increases deposition of ECM and promotes myofibroblast differentiation. With significantly reduced TGF $\beta$ in tendon disease, it might be expected that CTGF would also be decreased. However, in the current study no significant difference was seen in CTGF mRNA expression between healthy and diseased tendons. It is possible that other signalling pathways could influence CTGF mRNA expression. It has been suggested that CTGF can be independently expressed via the IL-13 pathway [57] which is implicated in alternative activation of macrophages. This is an interesting observation in light of the high levels of monocytes and macrophages observed in chronic rotator cuff tendinopathy [22].

BMPs are a sub-group of the TGF $\beta$ superfamily and are known to play developmental and homeostatic functions in most tissues [58]. BMP-2 and -7 have been shown to increase collagen production in rotator cuff cells, and could both be implicated in a fibrotic phenotype [33]. Furthermore BMP-2 may, like TGF $\beta$, be increased in response to strain [59]. However, we found no significant difference in mRNA expression of $B M P 2$ or $B M P 7$ in healthy and diseased tendons.

There are several limitations to this study. We did not investigate expression of other isoforms of TGF $\beta$ including TGF $\beta-2$ and TGF $\beta-3$ or expression of phosphoSMAD signalling. The samples from the current study were obtained from patients with established tendon disease. It is necessary to ascertain the temporal nature of TGF $\beta$ signalling in the more acute stage of tendinopathy and early stages of fibrosis. However, acquiring these samples of early-stage human tendon disease presents a number of challenges. We acknowledge there are limitations with the use of the hamstring tendon as a comparator to diseased tendons including tendon type and age differences. However, hamstring tendon was taken from live healthy donors with no history of tendon disease. We believe this is a more suitable comparator than cadaveric rotator cuff tendon tissues where little is known about whether the tendons were healthy or diseased and the influence of postmortem change.

The findings from our study showing downregulation of TGF $\beta$ superfamily members in established disease suggest that these patients are unlikely to benefit from therapeutic TGF $\beta$ blockade, which has been investigated as a treatment strategy in several animal models. Improved understanding of fibrotic processes in diseased human tendons is essential to inform therapeutic target discovery. Future studies should focus on investigating the expression profiles and mechanisms of fibrosis in tendon tissues obtained from longitudinal patient cohorts, from early to advanced disease and both before and after treatment.

\section{Conclusions}

We demonstrate dysregulation of the TGF $\beta$ axis in chronic human rotator cuff tendon disease and propose this may be a protective mechanism to further limit fibrosis. Our findings also suggest TGF $\beta$ pathways may have an important role in tendon homeostasis. Further work is needed to investigate TGF $\beta$-related pathways in healthy and diseased tendons, their roles in early-stage tendon pathology and the contribution of alternative pathways in the development of tendon fibrosis.

\section{Abbreviations \\ ACL: Anterior cruciate ligament; BMP: Bone morphogenic protein; CD: Cluster of differentiation; CTGF: Connective tissue growth factor; DAB: 3,3'-Diaminobenzidine; DNA: Deoxyribonucleic acid; ECM: Extracellular matrix; EMT: Epithelial-mesenchymal transition; Ig: Immunoglobulin; IL: Interleukin; NSAID: Non-steroidal anti-inflammatory drug; OSS: Oxford shoulder score; PBS: Phosphate-buffered saline; PRP: Platelet-rich plasma; qPCR: Quantitative polymerase chain reaction; RNA: Ribonucleic acid; STAT: Signal transducer and activator of transcription; TGF: Transforming growth factor; TGF R: Transforming growth factor receptor.}

\section{Competing interests}

The authors declare that they have no competing interests.

\section{Authors' contributions}

Study concept and design: SGD, AJC, SJBS, HCJG. Acquisition of data: HCJG, SGD. Analysis and interpretation of data: HCJG, SGD, SJBS, AJC. Drafting of the manuscript: All authors. Critical revision of the manuscript and approval of final version: All authors. Statistical analysis: HCJG, SGD. Obtained funding: AJC, SGD. Administrative, technical or material support: LR, KW, BW.

\section{Acknowledgements}

The Girdlestone Scholarship and NIHR Oxford Musculoskeletal Biomedical Research Unit funded this work. SGD and SJBS are funded by Arthritis Research UK grants 20506 and 20087, respectively. 


\section{Received: 3 December 2015 Accepted: 1 February 2016}

\section{Published online: 17 February 2016}

\section{References}

1. Vos T, Barber RM, Bell B, Bertozzi-Villa A, Biryukov S, Bolliger I, et al. Global, regional, and national incidence, prevalence, and years lived with disability for 301 acute and chronic diseases and injuries in 188 countries, 1990-2013: a systematic analysis for the Global Burden of Disease Study 2013. Lancet. 2015:386:743-800

2. Urwin M, Symmons D, Allison T, Brammah T, Busby H, Roxby M, et al. Estimating the burden of musculoskeletal disorders in the community: the comparative prevalence of symptoms at different anatomical sites, and the relation to social deprivation. Ann Rheum Dis. 1998;57:649-55.

3. Van der Windt DA, Koes BW, Boeke AJ, Devillé W, De Jong BA, Bouter LM. Shoulder disorders in general practice: prognostic indicators of outcome. Br J Gen Pract. 1996;46:519-23.

4. Chard MD, Hazleman R, Hazleman BL, King RH, Reiss BB. Shoulder disorders in the elderly: a community survey. Arthritis Rheum. 1991;34:766-9.

5. Kannus P. Etiology and pathophysiology of chronic tendon disorders in sports. Scand J Med Sci Sports. 2007;7:78-85.

6. Yamamoto A, Takagishi K, Osawa T, Yanagawa T, Nakajima D, Shitara H, et al. Prevalence and risk factors of a rotator cuff tear in the general population. J Shoulder Elbow Surg. 2010;19:116-20.

7. Xu Y, Murrell GAC. The basic science of tendinopathy. Clin Orthop Relat Res. 2008;466:1528-38.

8. Chaudhury S, Gwilym SE, Moser J, Carr AJ. Surgical options for patients with shoulder pain. Nat Rev Rheumatol. 2010;6:217-26.

9. Post M, Silver R, Singh M. Rotator cuff tear. Diagnosis and treatment. Clin Orthop Relat Res. 1983;173:78-91.

10. Józsa L, Réffy A, Kannus P, Demel S, Elek E. Pathological alterations in human tendons. Arch Orthop Trauma Surg. 1990;110:15-21.

11. Kannus P, Józsa L. Histopathological changes preceding spontaneous rupture of a tendon. A controlled study of 891 patients. J Bone Joint Surg Am. 1991;73:1507-25.

12. Dakin SG, Smith RKW, Heinegård D, Önnerfjord P, Khabut A, Dudhia J. Proteomic analysis of tendon extracellular matrix reveals disease stage-specific fragmentation and differential cleavage of COMP (cartilage oligomeric matrix protein). J Biol Chem. 2014;289:4919-27.

13. Matthews TJW, Hand GC, Rees JL, Athanasou NA, Carr AJ. Pathology of the torn rotator cuff tendon. Reduction in potential for repair as tear size increases. J Bone Joint Surg (Br). 2006;88:489-95.

14. Dean BJF, Franklin SL, Murphy RJ, Javaid MK, Carr AJ. Glucocorticoids induce specific ion-channel-mediated toxicity in human rotator cuff tendon: a mechanism underpinning the ultimately deleterious effect of steroid injection in tendinopathy? Br J Sports Med. 2014:48:1620-6.

15. Galatz LM, Ball CM, Teefey SA, Middleton WD, Yamaguchi K. The outcome and repair integrity of completely arthroscopically repaired large and massive rotator cuff tears. J Bone Joint Surg Am. 2004;86-A:219-24.

16. Aliprantis AO, Wang J, Fathman JW, Lemaire R, Dorfman DM, Lafyatis R, et al. Transcription factor T-bet regulates skin sclerosis through its function in innate immunity and via IL-13. Proc Natl Acad Sci U S A. 2007;104:2827-30.

17. Chiaramonte MG, Donaldson DD, Cheever AW, Wynn TA. An IL-13 inhibitor blocks the development of hepatic fibrosis during a T-helper type 2dominated inflammatory response. J Clin Invest. 1999;104:777-85.

18. Yamamoto T, Noble NA, Miller DE, Border WA. Sustained expression of TGF- $\beta 1$ underlies development of progressive kidney fibrosis. Kidney Int. 1994;45:916-27.

19. Wynn TA. Common and unique mechanisms regulate fibrosis in various fibroproliferative diseases. J Clin Invest. 2007;117:524-9.

20. Lee CG, Homer RJ, Zhu Z, Lanone S, Wang X, Koteliansky V, et al. Interleukin-13 induces tissue fibrosis by selectively stimulating and activating transforming growth factor beta(1). J Exp Med. 2001;194:809-21.

21. Gordon KJ, Blobe GC. Role of transforming growth factor-beta superfamily signaling pathways in human disease. Biochim Biophys Acta. 2008;1782:197-228.

22. Dakin SG, Martinez FO, Yapp C, Wells G, Oppermann U, Dean BJF, et al. Inflammation activation and resolution in human tendon disease. Sci Transl Med. 2015;7:311ra173.

23. Millar NL, Hueber AJ, Reilly JH, Xu Y, Fazzi UG, Murrell GAC, et al. Inflammation is present in early human tendinopathy. Am J Sports Med. 2010;38:2085-91.
24. Chang J, Thunder R, Most D, Longaker MT, Lineaweaver WC. Studies in flexor tendon wound healing: neutralizing antibody to TGF-beta1 increases postoperative range of motion. Plast Reconstr Surg. 2000;105:148-55.

25. Duffield JS, Forbes SJ, Constandinou CM, Clay S, Partolina M, Vuthoori S, et al. Selective depletion of macrophages reveals distinct, opposing roles during liver injury and repair. J Clin Invest. 2005;115:56-65.

26. Lu L, Saulis AS, Liu WR, Roy NK, Chao JD, Ledbetter S, et al. The temporal effects of anti-TGF-beta1, 2, and 3 monoclonal antibody on wound healing and hypertrophic scar formation. J Am Coll Surg. 2005;201:391-7.

27. Ma CB, Kawamura S, Deng X-H, Ying L, Schneidkraut J, Hays P, et al. Bone morphogenetic proteins-signaling plays a role in tendon-to-bone healing: a study of rhBMP-2 and noggin. Am J Sports Med. 2007;35:597-604

28. Shah M, Foreman DM, Ferguson MW. Neutralisation of TGF-beta 1 and TGF-beta 2 or exogenous addition of TGF-beta 3 to cutaneous rat wounds reduces scarring. J Cell Sci. 1995;108(Pt 3):985-1002.

29. Xia C, Ding C, Yang X, Sun K, Tian S. Effects of antisense transforming growth factor-beta1 gene transfer on the biological activities of tendon sheath fibroblasts. Orthopedics. 2010;33. doi:10.3928/01477447-20100625-06.

30. Katzel EB, Wolenski M, Loiselle AE, Basile P, Flick LM, Langstein HN, et al. Impact of Smad3 loss of function on scarring and adhesion formation during tendon healing. J Orthop Res. 2011;29:684-93.

31. Martinek V, Latterman C, Usas A, Abramowitch S, Woo SL-Y, Fu FH, et al. Enhancement of tendon-bone integration of anterior cruciate ligament grafts with bone morphogenetic protein-2 gene transfer: a histological and biomechanical study. J Bone Joint Surg Am. 2002;84-A:1123-31.

32. Mihelic R. Bone morphogenetic protein-7 (osteogenic protein-1) promotes tendon graft integration in anterior cruciate ligament reconstruction in sheep. Am J Sports Med. 2004;32:1619-25.

33. Pauly S, Klatte F, Strobel C, Schmidmaier G, Greiner S, Scheibel M, et al. BMP-2 and BMP-7 affect human rotator cuff tendon cells in vitro. J Shoulder Elbow Surg. 2012;21:464-73.

34. Dawson J, Fitzpatrick R, Carr A. Questionnaire on the perceptions of patients about shoulder surgery. J Bone Jt Surg Br. 1996;78-B:593-600.

35. Murphy RJ, Eng M, John B, Dean F, Ed M, Wheway K, Watkins B, Morrey ME, Carr AJ. A novel minimally invasive ultrasound-guided technique to biopsy supraspinatus tendon. Operat Tech Orthop. 2013:23:56-62.

36. Rizzardi AE, Johnson AT, Vogel RI, Pambuccian SE, Henriksen J, Skubitz AP, et al. Quantitative comparison of immunohistochemical staining measured by digital image analysis versus pathologist visual scoring. Diagn Pathol. 2012;7:42

37. Ruifrok AC, Johnston DA. Quantification of histochemical staining by color deconvolution. Anal Quant Cytol Histol. 2001;23:291-9.

38. Scott PG, Dodd CM, Tredget EE, Ghahary A, Rahemtulla F. Immunohistochemical localization of the proteoglycans decorin, biglycan and versican and transforming growth factor- $\beta$ in human post-burn hypertrophic and mature scars. Histopathology. 1995;26:423-31.

39. Wang R, Ghahary A, Shen Q, Scott PG, Roy K, Tredget EE. Hypertrophic scar tissues and fibroblasts produce more transforming growth factor-beta1 mRNA and protein than normal skin and cells. Wound Repair Regen. 2000;8:128-37.

40. Bonniaud P, Margetts PJ, Ask K, Flanders K, Gauldie J, Kolb M. TGF-beta and Smad3 signaling link inflammation to chronic fibrogenesis. J Immunol. 2005;175:5390-5.

41. Klein MB, Yalamanchi N, Pham H, Longaker MT, Chan J. Flexor tendon healing in vitro: effects of TGF- $\beta$ on tendon cell collagen production. J Hand Surg [Am]. 2002;27:615-20.

42. Willis BC, Borok Z. TGF-beta-induced EMT: mechanisms and implications for fibrotic lung disease. Am J Physiol Lung Cell Mol Physiol. 2007;293:L525-34.

43. Maeda T, Sakabe T, Sunaga A, Sakai K, Rivera AL, Keene DR, et al. Conversion of mechanical force into TGF- $\beta$-mediated biochemical signals. Curr Biol. 2011;21:933-41.

44. Heinemeier K, Langberg $H$, Olesen $J$, Kjaer M. Role of TGF-beta1 in relation to exercise-induced type I collagen synthesis in human tendinous tissue. J Appl Physiol. 2003;95:2390-7.

45. Sakai H, Fujita K, Sakai Y, Mizuno K. Immunolocalization of cytokines and growth factors in subacromial bursa of rotator cuff tear patients. Kobe $\mathrm{J}$ Med Sci. 2001:47:25-34.

46. Fenwick SA, Curry V, Harrall RL, Hazleman BL, Hackney R, Riley GP. Expression of transforming growth factor-beta isoforms and their receptors in chronic tendinosis. J Anat. 2001;199:231-40. 
47. Cui W, Fowlis DJ, Cousins FM, Duffie E, Bryson S, Balmain A, et al. Concerted action of TGF-beta 1 and its type II receptor in control of epidermal homeostasis in transgenic mice. Genes Dev. 1995;9:945-55.

48. Finnson KW, Chi Y, Bou-Gharios G, Leask A, Philip A. TGF-b signaling in cartilage homeostasis and osteoarthritis. Front Biosci (Schol Ed). 2012:4:251-68.

49. Omori E, Matsumoto K, Sanjo H, Sato S, Akira S, Smart RC, et al. TAK1 is a master regulator of epidermal homeostasis involving skin inflammation and apoptosis. J Biol Chem. 2006;281:19610-7.

50. ten Dijke P, Arthur HM. Extracellular control of TGFbeta signalling in vascular development and disease. Nat Rev Mol Cell Biol. 2007;8:857-69.

51. Harradine KA, Akhurst RJ. Mutations of TGF $\beta$ signaling molecules in human disease. Ann Med. 2006;38(6):403-14.

52. Verjee LS, Verhoekx JSN, Chan JKK, Krausgruber T, Nicolaidou V, Izadi D, et al. Unraveling the signaling pathways promoting fibrosis in Dupuytren's disease reveals TNF as a therapeutic target. Proc Natl Acad Sci U S A. 2013;110:E928-37.

53. Chang J, Most D, Stelnicki E, Siebert JW, Longaker MT, Hui K, et al. Gene expression of transforming growth factor beta-1 in rabbit zone II flexor tendon wound healing: evidence for dual mechanisms of repair. Plast Reconstr Surg. 1997;100:937-44.

54. Kobayashi M, Itoi E, Minagawa H, Miyakoshi N, Takahashi S, Tuoheti Y, et al. Expression of growth factors in the early phase of supraspinatus tendon healing in rabbits. J Shoulder Elbow Surg. 2006;15:371-7.

55. Gong D, Shi W, Yi S, Chen H, Groffen J, Heisterkamp N. TGF $\beta$ signaling plays a critical role in promoting alternative macrophage activation. BMC Immunol. 2012;13:31.

56. Katsura T, Tohyama H, Kondo E, Kitamura N, Yasuda K. Effects of administration of transforming growth factor (TGF)-beta1 and anti-TGFbeta1 antibody on the mechanical properties of the stress-shielded patellar tendon. J Biomech. 2006;39:2566-72.

57. Liu Y, Meyer C, Müller A, Herweck F, Li Q, Müllenbach R, et al. IL-13 induces connective tissue growth factor in rat hepatic stellate cells via TGF- $\beta$ independent Smad signaling. J Immunol. 2011;187:2814-23.

58. Wang RN, Green J, Wang Z, Deng Y, Qiao M, Peabody M, et al. Bone morphogenetic protein (BMP) signaling in development and human diseases. Genes Dis. 2014:1:87-105.

59. Rui YF, Lui PPY, Ni M, Chan LS, Lee YW, Chan KM. Mechanical loading increased BMP-2 expression which promoted osteogenic differentiation of tendon-derived stem cells. J Orthop Res. 2011;29:390-6.

\section{Submit your next manuscript to BioMed Central and we will help you at every step:}

- We accept pre-submission inquiries

- Our selector tool helps you to find the most relevant journal

- We provide round the clock customer support

- Convenient online submission

- Thorough peer review

- Inclusion in PubMed and all major indexing services

- Maximum visibility for your research

Submit your manuscript at www.biomedcentral.com/submit 